\title{
A estruturação do Complexo Industrial-Militar-Biotecnológico e a questão da hegemonia norte-americana no século XXI
}

\author{
The structure of the military-industrial-complex-biotech and \\ the American hegemony in the century XXI
}

\section{La estructura del complejo militar-industrial de biotecnología y la cuestión de la hehemonía EE.UU. en el siglo XXI}

\author{
Douglas Rundvalt \\ douglasrundvalt@yahoo.com.br \\ Universidade Estadual de Ponta Grossa \\ Edu Silvestre Albuquerque \\ edusilvestre@ufrnet.br \\ Universidade Federal do Rio Grande do Norte
}

Resumo: A ligação entre militares, políticos e empresários das indústrias farmacêuticas e de biotecnologia emerge como novo padrão de reprodução capitalista na atualidade a partir das relações ditadas no centro do sistema. Propomos, assim, a expansão do conceito de Complexo Industrial-Militar cunhado por Eisenhower de modo a abarcar o setor farmacêutico e biotecnológico, mais adequadamente tratado de Complexo Industrial-Militar-Biotecnológico na atualidade. Desse modo, desvelamos o papel das empresas de biotecnologia na reestruturação econômico-territorial em curso nos Estados Unidos, como alternativa conservadora de saída da crise econômica atual.

Palavras-chave: Defesa. Biodefesa. Complexo Militar. Biotecnologia.

Abstract: The connection between, military, political and businessmen of the pharmaceutical and biotechnology emerges like new pattern capitalist reproduction current relations dictated from the center of the system. I there propose the expansion of concept of military-industrial complex Eisenhower coined to encompass the pharmaceutical industry and biotechnology, more adequately treated in the militaryindustrial-complex-biotech today. Thus, were the revealed the role of biotechnology companies in the economic and territorial restructuring current in the United States as an alternative conservatively output current economic crisis.

Keywords: Defense. Biodefense. Military Complex. Biotechnology.

Resumen: La relación entre los líderes militares, políticos y empresaliares de la industria farmacêutica y la biotecnologia surge como um nuevo nivel de la reprodución capitalista em lãs relaciones actuales dictados desde el centro del sistema. Propongo, pues, la expansión del concepto de complejo industrial-militar acuñado por Eisenhower para englobar la industria farmacéutica y la biotecnología, abordam mas adecuadamente complejo militar-industrial de biotecnología em la actualidad. Por lo 
tanto, se dieram a conocer el papel de las empresas de biotecnología en el curso de reestructuración económica y territorial en los Estados Unidos, como una alternativa de salida conservadora actual crisis económica.

Palabras clave: Defense. Biodefense. Complejo Militar. Biotecnología.

\section{INTRODUÇÃO}

As articulações entre militares, políticos e empresários das indústrias farmacêuticas e biotecnológicas são investigadas no contexto da emergência de um novo padrão de reprodução capitalista a partir dos Estados Unidos, uma saída conservadora para a nova crise sistêmica capitalista. O objetivo principal é descrever qualitativamente esse processo de reestruturação econômico-territorial em curso a partir do Complexo Industrial-MilitarBiotecnológico (CIMB), uma ramificação do Complexo Industrial-Militar (CIM), conceito cunhado pelo presidente norte-americano D. Eisenhower no final da década de 1950. Essa atualização conceitual é necessária porque o CIM tradicional não representa mais o suporte necessário para explicar o avanço das pesquisas militares, sobretudo nos setores de fármacos e biotecnologia.

Para compreender essa reestruturação econômico-territorial em curso no centro do sistema, resgata-se o conceito de hegemonia, agora aplicado a organização do sistema internacional. A Teoria da Estabilidade Hegemônica (TEH), elaborada por Gilpin (1987), afirma a necessidade da estabilidade e segurança internacional por meio de um ator hegemônico. Essa reprodução das condições de hegemonia exige que a nação líder aponte saídas sistêmicas para resolver a crise de acumulação iniciada em seu centro, que D. Harvey (2003) aponta atualmente no resgate da "acumulação por espoliação".

O desenvolvimento tecnológico tem sido uma saída para as crises capitalistas provocadas pela tendência da queda da taxa de lucros em situações de capitais sobre acumulados. Marx já descrevera este processo no século XIX, e as suas grandes guerras mundiais ocorridas no século XX desenvolvem subitamente as tecnologias duais a partir dos desenvolvimentos militares. Isso ocorreu durante todo o período da Guerra Fria, onde as duas superpotências encetaram uma insana corrida armamentista, e também ao final da crise das décadas de 1970-80, momentos em que se pode perceber o poder reestruturador produtivo-territorial do capitalismo a partir dos Estados Unidos.

$\mathrm{Na}$ última grande crise dos anos 70, os EUA encetaram uma aliança estratégica com a China para a retomada das taxas médias históricas de lucros, baseada na exportação de capitais para o desenvolvimento do setor industrial chinês e no retorno desses capitais na forma de compra de títulos da dívida pública para, sob a égide do governo norteamericano, alavancar as novas tecnologias (high techonology) emergidas do CIM. Em termos geopolíticos, esse movimento ocasionou o isolamento político e econômico da URSS, encerrando a Guerra Fria, e hoje, leva o modelo do welfare state europeu ao colapso diante da contínua inundação dos mercados mundiais com bens de consumo não-duráveis produzidos na China (FIORI, 2005). 
Entretanto, a hegemonia norte-americana no período pós Guerra Fria não se faz sem sobressaltos. O crescimento econômico oportunizado pela globalização tem arrefecido especialmente nos países centrais, provocando nova crise de reprodução sistêmica do capitalismo. No plano simbólico, assim como a Guerra do Vietnã marcou o momento de crise e a necessidade de superação para repor a hegemonia ameaçada nos anos 1970, os atentados terroristas do 11 de setembro de 2001 às torres símbolos do capital financeiro (World Trade Center) e ao Pentágono (Defesa dos EUA) representam nova oportunidade para a continuidade da hegemonia norte-americana no atual século ${ }^{1}$.

Nesse sentido, a retomada dos investimentos na indústria da defesa aos níveis da Guerra Fria vem com a invasão do Afeganistão e do Iraque, e mais recentemente, com as ações da OTAN na Líbia, alegadamente para deter os "Estado-Párias", e pode-se dizer, ainda com a ampliação do cercamento militar da Rússia, China e Irã (ALBUQUERQUE, 2011). Nessa necessidade de novas guerras reside a justificativa para a continuidade dos investimentos militares em novas tecnologias, sobretudo diante das limitações ao desenvolvimento de armas atômicas definidas por tratados internacionais. Esta é a ponta do iceberg que se descortina com a entrada em cena de Donald Rumsfeld - conhecido como "senhor das guerras" do governo republicano de George Bush -, durante o episódio da ameaça de uma pandemia de gripe global.

O primeiro estudo de caso investiga o projeto do escudo de Biodefesa (Bioshield Two), elaborado em 2007, e apresentado ao senado norte-americano (2004) para supostamente sanar as irregularidades do primeiro projeto de Biodefesa elaborado ainda no governo Bush. O projeto original disponibilizaria perto dos US\$ 6 bilhões para que o governo norte-americano investisse em vacinas contra o antraz, supostamente para prevenir possíveis ataques bioterroristas à população civil e aos militares estacionados em zonas conflagradas do Iraque e Afeganistão. A principal favorecida era a empresa de biotecnologia VaxGen, recebendo um montante de quase 900 milhões de dólares para a produção de 75 milhões de doses da vacina contra o Antraz (com entrega de 25 milhões de doses dois anos após o fechamento do contrato $)^{2}$. Devido a irregularidades e erros cometidos, o projeto sofreu críticas e interrupções, sendo retomado em 2007, agora renomeado de "Project Bioshield Two".

O segundo estudo de caso aborda a relação íntima entre o neoconservador republicano e secretário de defesa Donald Rumsfeld com a empresa produtora do TAMIFLU. Em 2004, antes mesmo da histeria da pandemia da gripe H1N1 - popularizada pela mídia como gripe suína -, Rumsfeld conseguia do senado norte-americano a aprovação do "Fundo de Emergência a uma Possível Pandemia Global", com montante

1 Em 1997 Samuel P. Huntington escreve o livro "O choque das civilizações", alertando sobre uma possível aliança entre chineses e muçulmanos e propondo uma estratégia de contenção ocidental através do uso da pressão política e econômica e da intervenção militar quando necessário (ALBUQUERQUE, 2011). A real intenção de Huntington é ocultar as verdadeiras razões geopolíticas e econômicas das nações líderes do Ocidente, onde o objetivo, especialmente norte-americano, é apoderar-se das ricas jazidas de petróleo da região e deter a expansão do poder militar chinês.

2 A empresa Vaxgen anuncia em novembro de 2004 que receberá, sozinha, uma ajuda de custo de 877,5 milhões de dólares para abastecer o mercado com 75 milhões de doses de vacina contra o antrax para defender a população civil. Disponível em http:/ / www.news-medical.net/news/2004/11/04/6115.aspx. Acessado em 15/10/2011. 
de US $\$ 7,1$ bilhões para a compra do medicamento TAMIFLU ${ }^{3}$. Rumsfeld fora presidente da empresa Gilead Sciences Inc., detentora da patente do TAMIFLU, deixando o cargo em 2001 para atender ao convite do presidente George W. Bush e tornar-se secretário de Defesa.

Com estes dois estudos de caso espera-se demonstrar essas ligações profundas e, mormente, promíscuas, entre militares, empresários das indústrias de biodefesa e o governo norte-americano. Aliás, o próprio termo biodefesa é referenciado por senadores norte-americanos em projetos de lei que prevêem somas bilionárias para a fabricação de vacinas contra "possíveis ataques terroristas" ou "pandemias da globalização".

A metodologia desenvolvida neste trabalho envolve a revisão da literatura sobre reestruturação econômico-territorial e o levantamento de dados secundários através do cruzamento de informações do site do senado norte-americano e da empresa Gilead Sciences Inc., cujo elo de ligação é a figura de Donald Rumsfeld, por sua posição estratégica no interior do CIMB como ex-empresário e autor do projeto do "Fundo de Emergência de Combate a uma Possível Pandemia Global". Assim, reconstruímos algumas dessas ligações dos lobbies das indústrias farmacêuticas e de biotecnologia no meio político e militar estadunidense.

\section{A (RE)ESTABILIZAÇÃO HEGEMÔNICA VIA ACUMULAÇÃO POR ESPOLIAÇÃO}

A emergência do Complexo Industrial-Militar-Biotecnológico (CIMB) ocorre num momento histórico semelhante ao dos anos 1970-80, onde os EUA investiram em tecnologia de uso dual (FIORI, 2007), e cujo efeito spin-off (DAGNINO, 2008) ocorreu com a conversão de tecnologias militares para uso civil, caso dos celulares, do GPS e da internet. Em verdade, as tecnologias do CIMB já vinham experimentando importante desenvolvimento no período da Guerra Fria, quando foram criados diversos laboratórios especializados na criação e produção de vírus, bactérias e vacinas em massa (MILLER, ENGELBERG e BROAD, 2002), e agora demonstram suas potencialidades de lucro no mercado civil para as empresas norte-americanas.

A fabricação, o transporte e a produção em massa de vírus e bactérias resultam em gastos menores se comparados às armas nucleares. Laboratórios foram criados para estudos biotecnológicos, massificando a produção de vírus e bactérias, bem como de antibióticos e vacinas para combater as doenças criadas e modificadas geneticamente nos laboratórios. O exemplo clássico desses laboratórios encontrava-se na base militar de Fort Detrick, em Maryland (MILLER, ENGELBERG e BROAD, p. 53, 2002).

Com a interrupção da longa fase de crescimento econômico mundial, alavancado pelo boom do comércio internacional, pela crise desde 2008, são resgatadas velhas táticas para que a potência hegemônica possa fugir novamente "para a frente". Assim, David

3 Disponível em http://www.lawrei.eu/MRA_Alliance/?p=3333 acessado em 05/10/2010. 
Harvey (2003) retoma os conceitos de acumulação por espoliação e de imperialismo, onde as guerras de intervenção na periferia visam à remoção dos obstáculos políticos ao movimento de capitais sobreacumulados nos países centrais.

A acumulação por espoliação decorre do excedente de capital ou capital ocioso dos países centrais, que necessita da liberação de um conjunto de ativos a um custo muito baixo. Um exemplo clássico de acumulação por espoliação foi o colonialismo europeu em terras africanas e sul-americanas, apropriando-se das terras indígenas para a exploração de metais preciosos. Outro exemplo de acumulação por espoliação é a biopirataria, com a apropriação da natureza e o patenteamento e licenciamento de material genético.

Portanto, o conceito de acumulação por espoliação é indissociável daquele de sobreacumulação de capital, e demonstra a capacidade sistêmica do país hegemon de reestruturar a economia global em tempos de crise. Assim como durante a Guerra Fria os CIM's baseavam seu poder na tomada de decisões políticas para reorientar o processo de reprodução ampliada do capital, muitas vezes, manipuladas pelos próprios militares norte-americanos; atualmente, o senado norte-americano coloca novamente em pauta a expansão dos CIM's, agora na forma de criação de uma "Indústria de Biodefesa" para proteger a população civil e as tropas militares norte-americanas estacionadas nos quatro cantos do mundo contra um possível ataque biológico, repetindo os ataques furtivos dos atentados de 11 de setembro de 2001.

Para alguns "teóricos da conspiração", a produção do medo nos EUA acerca de ataques biológicos foi orquestrada ainda a partir do próprio establishment dos CIM's, alegando-se que até hoje não se descobriu a autoria das diversas cartas contendo Antraz que foram entregues via correio para diversos órgãos públicos, apesar de sua "assinatura química" reportar para laboratórios norte-americanos do período da Guerra Fria.

As ações militaristas do país hegemon precisam ser aceitas pela comunidade internacional, então disfarçada de discurso da hegemonia benevolente (FIORI, 2007) ou da coerção consentida (HARVEY, 2003). Desta forma, a hegemonia benevolente mescla interesses políticos e militares ao mobilizar instrumento do soft power para convencer outros países quanto ao exercício benéfico do poder do hegemon (GARCIA, 2010).

Os discursos de "guerra contra o terrorismo" ocultam justamente o propósito de justificar as coalizões lideradas pelos Estados Unidos ou pela OTAN contra governos hostis do Oriente Médio e Norte da África. Assim, neste começo de século, Afeganistão, Iraque e Líbia sofreram intervenções militares "ocidentais" sob o pretexto de erradicação do terrorismo e implantação da democracia, quando o objetivo maior era a apropriação das jazidas petrolíferas e gasíferas destes países para a exploração das mesmas por empresas ocidentais (HARVEY, 2003).

Essa retomada da acumulação por espoliação pelos Estados Unidos viabiliza nova expansão dos CIM's, especialmente pelo uso das tecnologias duais para desenvolver mercados civis, agora unindo políticos, militares e empresários da indústria farmacêutica e de biotecnologia na forma de lobbies juntos ao congresso norte-americano (FLORES, 2002). Os bilionários investimentos públicos nos CIMB's viabilizam a reestruturação econômico-territorial na América, cujos efeitos poderão reverberar por todo o mundo. 


\section{O PROJETO BIOSHIELD TWO}

Os atentados de 11 de setembro de $2001^{4}$ são apontados como marco do inicio da crise de hegemonia norte-americana ao sinalizar uma contestação mais aberta a esta liderança. A Teoria da Estabilidade Hegemônica (TEH) de Robert Gilpin (1987), afirma a necessidade de uma potência hegemônica para estabilizar e manter aberta a economia mundial, e é esta a missão histórica que os Estados Unidos buscam com as intervenções militares no Oriente Médio Expandido.

Paralelamente a reação militar norte-americana aos ataques terroristas, o governo Bush lançou o "Project Bioshield" (Projeto Escudo da Biodefesa), sancionado em 2004, que previa o repasse de quase 6 bilhões de dólares para a produção de doses da vacina contra a bactéria do Antraz ${ }^{5}$. Cerca de US\$ 5,6 bilhões foram destinados ao Projeto de Biodefesa, e um quinto deste valor a uma única empresa, a VaxGen, para a produção em massa de doses da vacina contra o Antraz 6 . A VaxGen era uma empresa de biotecnologia de pequeno porte, que tornava-se conhecida devido a esse projeto. Na sequência, a VaxGen realiza uma fusão com outra empresa de biotecnologia, a Diadexus ${ }^{7}$.

Após uma curta interrupção do Projeto de Biodefesa, ele é retomado em 2007, quando o senador Joe Lieberman apresenta ao congresso o "Project Bioshield: Actions Needed to Avoid Repeatings Past Mistakes" (23/10/2007). Neste relatório, o congressista ressalta a necessidade de retomar o projeto, pois tanto a população civil quanto os militares estariam a mercê de novos ataques bioterroristas:

ASPR is responsible for the entire Project BioShield contracting process, including issuing requests for information and requests for proposals, awarding contracts, managing awarded contracts, and determining whether contractors have met the minimum requirements for payment. ASPR maintains a Web site detailing all Project Bioshield solicitations and awards (PROJECT BIOSHIELD 2007, p. 7).

A proposta de retomada do Projeto de Biodefesa ficou conhecida como "Bioshield Two". A ASPR (Sociedade Americana de Pesquisas Científicas) tornar-se-ia o órgão regulador das atividades de produção e estocagem dos materiais, para evitar os erros e irregularidades cometidos no passado. Os três fatores listados que contribuíram para o fracasso do projeto anterior foram:

4 Para Vesentini, estamos presenciando uma "segunda onda" de atentados terroristas movida pelo que ele chama de "terroristas pós-modernos" (2002, p. 279), pois, diferentemente do que ocorria no inicio do séc. XX, quando os terroristas praticavam seus atentados contra pessoas públicas e elites locais, os atuais terroristas não possuem um objetivo concreto como a derrubada do Estado, mas apenas declaram "guerra ao ocidente" e aos aliados dos EUA.

5 Essas informações percorreram vários meios de comunicação na época, e a esperança do governo Bush era de que a população estadunidense ficasse mais tranquila e protegida contra possíveis ataques terroristas. Disponível em http://www.bbc. co.uk/portuguese/reporterbbc/story/2004/07/040721_washingtonng.shtml. Acessado em 09/10/2011.

6 Disponível http://www.news-medical.net/news/2004/11/04/6115.aspx. Acessado em 09/19/2011.

7 No mundo globalizado a onda de fusões entre grandes empresas tornam-se o cerne dessa nova fase do sistema capitalista, o capitalismo financeiro. Disponível em http://www.news-medical.net/news/20100529/25/Portuguese.aspx. Acessado em 09/10/2011. 
First, ASPR awarded the first BioShield procurement contract to VaxGen when its product was at a very early stage of development and many critical manufacturing issues had not been addressed. Second, VaxGen took unrealistic risks in accepting the contract terms. Third, key parties did not clearly articulate and understand critical requirements at the outset. (idem, p. 8).

Percebe-se que a empresa VaxGen é citada quando mencionado o estágio inicial das pesquisas para a elaboração da vacina contra o Antraz, que não deveria ser delegado à uma empresa tão pequena essa gigantesca responsabilidade, pois os estudos para a fabricação e produção dessa vacina estariam em estágio embrionário. O documento cita ainda que a empresa não realizou as pesquisas necessárias, nem atingiu resultados de eficácia da vacina. Outra irregularidade apontada no primeiro projeto é de que o governo exigia a fabricação de 75 milhões de doses da vacina, porém, a empresa deveria entregar apenas $1 / 3$ ou 25 milhões de doses em dois anos ${ }^{8}$.

Outro apontamento que chama atenção foram as justificativas da ASPR quando perguntada da escolha dessa empresa, alegando a urgência da fabricação e produção do medicamento, e que as chances de sucesso giravam em torno de 80 a $90 \%$, quando o discurso da própria empresa era de que as chances de sucesso estariam apenas entre 10 a 15\% justamente pelo fato de que suas pesquisas ainda estavam num estágio embrionário ${ }^{9}$. Mas determinadas lideranças políticas norte-americanas não desejavam esperar mais tempo, demonstrando a influência dos lobbies na afirmação do emergente CIMB.

\section{DONALD RUMSFELD E O CASO TAMIFLU}

Entre 2008 e 2009, a mídia internacional noticiou uma suposta elevada letalidade do vírus da gripe H1N1, associada a sua característica de pandemia global, provocando verdadeira histeria planetária ${ }^{10}$. Falava-se inclusive na repetição da terrível gripe espanhola, que dizimou parcela expressiva da população ocidental no inicio do século passado.

Em 2005, outra histeria fabricada havia sido ensaiada com o surto da gripe aviária. Mas foi com o H1N1, que o governo Bush alcançou criar o bilionário "Fundo de Emergência para Combate a uma possível Pandemia Global", base financeira de novos ramos do CIMB. Seu secretário de Defesa da época, Donald Rumsfeld, foi justamente

8 ASPR's decision to launch the VaxGen procurement contract for the rPA anthrax vaccine at an early stage of development, combined with the delivery requirement for 25 million doses within 2 years, did not take the complexity of vaccine development into consideration and was overly aggressive. Citing the urgency involved, ASPR awarded the procurement contract to VaxGen several years before the planned completion of earlier (2007, p. 8).

9 At the time of the award, ASPR officials had no objective criteria, such as Technology Readiness Levels (TRL), to assess product maturity. They were, however, optimistic that the procurement contract would be successful. One official described its chances of success at 80 percent to 90 percent. However, a key official at VaxGen told us at the same time that VaxGen estimated the chances of success at 10 percent to 15 percent. When we asked ASPR officials why they awarded the procurement contract when they did, they pointed to a sense of urgency at that time and the difficulties in deciding when to launch procurement contracts $(2007$, p. 9).

10 Um dos principais meios de comunicação on-line brasileiro noticiou de três a quatro vezes por dia, entre junho e julho de 2009, sobre a possibilidade da pandemia H1N1 chegar ao país. Noticiava ainda quase que instantaneamente os casos de óbito ocorridos no país naquele ano. Disponível em http:/ /veja.abril.com.br/noticia/saude/arquivo. Acessado em 11/09/2009. 
o presidente da empresa Gilead Sciences Inc. no período de 1997 a 2001, e atualmente possui ações dessa companhia. Essa empresa de biotecnologia era quem detinha os direitos patenteados ${ }^{11}$ do antiviral TAMIFLU, o único medicamento reconhecido oficialmente como eficiente para o tratamento da gripe H1N1.

“Adepto às ideias da 'Escola de Chicago' e amigo íntimo do economista liberal Martin Friedman, veteranos 'senhor das guerras' e de intervenções no chamado "tratamento de choque' econômico" (KLEIN, 2008, p. 17), Rumsfeld sempre fora ligado à política, iniciando sua carreira pública aos 25 anos, em 1957, como assistente no Congresso dos EUA. Em 1962, foi eleito deputado pelo Partido Republicano, e reeleito, sucessivamente, em 1964, 1966 e 1968. Como adepto dos ideais republicanos, sempre defendeu a política de defesa, o que lhe rendeu em pouco tempo o respeito dos militares ${ }^{12}$. Em 1975, torna-se o mais jovem secretário de Defesa dos EUA, e nesse momento já intervêm militarmente no Chile do então presidente Salvador Allende com sua 'terapia de choque' seguido pelo caos econômico no país onde "medo e desordem são os catalisadores de um novo salto para frente (KLEIN, 2008, p. 18), forçando o Chile para a abertura econômica e adesão ao livre-comércio, sendo esse um dos episódios que marcam a grande influência de Donald Rumsfeld no meio político e militar estadunidense.

Rumsfeld afastara-se da vida política brevemente em razão da ascensão dos democratas ao poder, então assumindo a administração da GD Searle (1977-1985), empresa do ramo farmacêutico de renome internacional. Durante sua administração, ganha importantes prêmios, como o Outstandin Chief Executive Office (1980). Paralelamente, presidia a General Instrument Corporation $(1980-81)^{13}$, empresa especializada na fabricação de produtos de alta tecnologia.

Em 1997, Rumsfeld assume a presidência do conselho da Gilead Sciences Inc., permanecendo até 2001, momento em que retorna à vida pública como secretário de Defesa de George W. Bush. No site da Gilead Sciences Inc., pode-se encontrar uma matéria sob o título "Donald H. Rumsfeld Named Chairman of Gilead Sciences"14 (Donald H. Rumsfeld nomeado presidente da Gilead Sciences Inc.) (Foster City, CA - January 3, 1997), relatando sua íntima ligação com as empresas de biotecnologia, o governo e os militares ${ }^{15}$.

De fato, Rumsfeld procurou favorecer as empresas pelas quais passou, mesclando interesses pessoais, políticos e por vezes militares, dois casos nos chamam a atenção nesse momento, o primeiro foi a aprovação extraodinária em Janeiro de 1981 do "Aspartame", um adoçante artificial. Relato da contido no site da Monsanto (empresa que comprou GD Searle e deteve a patente desse produto até 1992) apresenta possíveis irregularidades na aprovação desse produto:

11 No momento em que o pânico dominava o mundo, a única empresa detentora da patente era a Gilead Science Inc., que junto com a Roche, produziam e comercializavam esse medicamento.

12 Disponível em http://www.biografiasyvidas.com/biografia/r/rumsfeld.htm. Acessado em 02/10/2010.

13 Disponível em http://www.defense.gov/specials/secdef_histories/bios/rumsfeld.htm. Acessado em 08/10/2010.

14 Donald Rumsfeld nomeado presidente da Gilead Sciences Inc. (Tradução nossa).

15 Disponível em http://www.gilead.com/wt/sec/pr_933190157/. Acessado em 19/05/2011. 
Em 1980, a U.S. Food and Drug Administration (FDA) concluiu que o aspartame não causa danos ao cérebro, mas não emitiu sua aprovação, citando dados insuficientes sobre câncer. Em 1981, a FDA confiou em informações de um estudo feito no Japão e aprovou o aspartame para uso em alguns alimentos secos. Em 1983, a FDA aprovou o uso do aspartame em bebidas com gás e alimentos assados. Antes de 1996, o aspartame obteve a aprovação da FDA para todos os produtos alimentícios ${ }^{16}$.

Possivelmente usando seu poder no meio político o presidente da GD Searle acelerou o processo para inserção desse produto ao mercado, gerando inúmeras discussões sobre os malefícios que esse produto causa nos seres humanos, no entanto esse assunto nos leva a outra discussão que não vêm ao caso nesse momento. Outro acontecimento que merece nossa atenção neste artigo, além de mais recente envolve diretamente, militares, políticos e uma empresa pela qual Rumsfeld presidiu até 2001 sendo ela a Gilead Sciences Inc. Os lucros dessa empresa tiveram um salto extraordinário já em 2005, arrecadando em torno de US\$ 1 bilhão, quantia quatro vezes maior do que um ano antes, quando sua receita alcançara US\$ 258 milhões. Esse sobressalto vertiginoso em sua arrecadação se deve em partes, ao fato de que Rumsfeld apresenta uma carta ao senado norte-americano alertando sobre a necessidade de proteger as tropas militares estacionadas pelo mundo contra essas novas gripes que surgiram. Incitando o governo norte-americano a criar o "Fundo de Emergência de Combate a uma Possível Pandemia Global" e ao mesmo tempo comprar 58 milhões de dólares em doses do TAMIFLU.

Em 2008, a Gilead Sciences Inc. anuncia outro boom em sua receita agora batendo em 5,34 bilhões de dólares, crescimento de $26 \%$ da receita em relação a 2007 . É perceptível nessa ascensão da arrecadação da empresa sua correspondência com os períodos das supostas pandemias gripais, quando vendas dos medicamentos antigripais ascendem na mesma proporção. O gráfico 1 apresenta justamente essa relação positiva entre a ascensão dos lucros da empresa Gilead Sciences Inc. nos anos de 2004 e 2005 com o suposto surto planetário da gripe aviária - ainda que particularmente centrada nos países asiáticos, e ainda nos anos de 2007 e 2008 com a "gripe suína”.

16 Informação disponível no próprio site da Monsanto http://www.monsanto.com.br/institucional/para_sua_informacao/ aspartame_nutrasweet.asp acessado em 20/05/2011 
Gráfico 1 - Lucros da Gilead Sciences Inc. de 2004 a 2008 - em bilhões de US\$

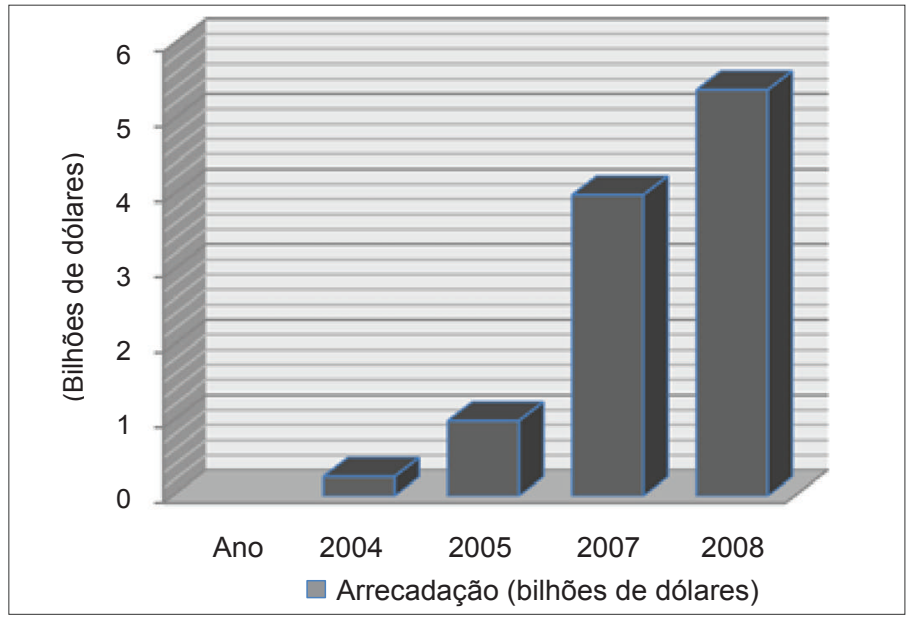

Percebe-se a ascensão dos lucros em períodos de medo de uma pandemia gripal a nível mundial nos anos de 2004-2005 e 2007-2008.

Org: RUNDVALT, 2011.

Apesar de uma das mais novas empresas no ramo da biotecnologia, iniciando seus trabalhos apenas em 1987, a Gilead Sciences Inc. já se destacava na produção de medicamentos para o tratamento do vírus HIV, além de comercializar várias drogas para o tratamento de gripes do tipo " $A$ " $\mathrm{e}$ " $B$ ". Mas mesmo com este portfólio, a empresa apresentou déficits no orçamento, até que em 1991 consegue financiamento privado para desenvolver bloqueadores no tratamento de câncer.

A empresa investiu em torno de 93 milhões de dólares, em 8 anos de pesquisa, para apresentar ao mercado seu primeiro produto, o VISTIDE, usado no tratamento de infecções nos olhos, de modo que em meados da década de 1990 seu crescimento já era inegável.

Mas essa extraordinária ascensão dos lucros da empresa somente ocorreu com uma maior aproximação com os políticos e o Estado norte-americano, por meio de compras governamentais direcionadas a seu portfólio. Somente então as vendas dos medicamentos patenteados pela empresa aumentaram em 501\% no curto intervalo de 1998 a 2001, antes mesmo do TAMIFLU ${ }^{17}$.

Com a explosão da demanda de antivirais capazes de conter uma possível pandemia global de gripe, a empresa procura por parcerias com concorrentes de porte mundial. Essas parcerias servem para aumentar a base de produção e a rede de comercialização de alguns medicamentos. É o caso da gigante Roche, com quem acabaria se fundindo para dar origem a uma das maiores parcerias mundiais no ramo. Conforme o site da própria Gilead Sciences Inc.:

(...) a ameaça global de uma pandemia de gripe aviária em potencial tem desafiado os governos, as autoridades de saúde pública e a indústria farmacêutica as quais se unem em parceria com o propósito de estabelecer um plano global de luta contra esta

17 Disponível em http://www.fundinguniverse.com/company-histories/Gilead-Sciences-Inc-Company-History.html acessado em 05/10/2010. 
doença mortal. Além desta ameaça, a gripe sazonal também aponta surtos e resulta em centenas de milhares de mortes anualmente em todo o mundo. E nesse momento a nossa disputa terminou com a Roche, em um esforço para trabalhar em conjunto, com a máxima diligência para resolver esta necessidade de saúde pública global $(16 / 11 / 2005)^{18}$.

Essas empresas anunciaram que a fusão se deu para a produção e comercialização em larga escala do antiviral TAMIFLU ${ }^{19}$, e ocorreu no mesmo mês e ano em que o senado norte-americano aprovava o "Fundo de Emergência para Combate e uma Possível Pandemia Global", depois do alerta do secretário de Defesa Donald Rumsfeld da necessidade de vacinação das tropas contra as novas gripes.

Essa fusão entre as duas gigantes visava encerrar as disputas comerciais entre ambas, aproveitando as oportunidades da exploração conjunta de mercados globais viabilizados pelo capitalismo financeiro e pela formação de monopólios internacionais. Nesse novo modelo, "as empresas deixam de lado a competição direta para explorarem novos mercados através do desenvolvimento de novas técnicas e da maximização das estruturas logísticas." (SANTOS, 2007, p. 46).

Uma externalidade ao governo norte-americano, é que ao "salvar o mundo" das pandemias gripais, fortalece-se o discurso de hegemonia benevolente dos Estados Unidos, o que acaba servindo de substrato ideológico para justificar a retomada do padrão de acumulação de capitais pela via da espoliação (HARVEY, 2003).

\section{CONSIDERAÇÕES FINAIS}

Neste artigo foram apresentados dois estudos de caso para iniciar uma discussão que vai além de meras "teorias conspiratórias", onde desvelamos as ligações entre militares, políticos e industriais nos Estados Unidos no atual período de crise de acumulação e de hegemonia.

Essas profundas ligações entre meio militar e político e as indústrias de biotecnologia foram demonstradas para o caso do Projeto Escudo de Biodefesa e em particular, na produção da vacina TAMIFLU. A intenção de manipular parte do orçamento público dos Estados Unidos em beneficio de umas poucas empresas e pessoas torna-se evidente nestes estudos de caso apresentados e que, de resto, parecem interligados.

Presenciamos uma espécie de dèja vu quando lembramos a denúncia do presidente D. Eisenhower, ainda na década de 1950, da manipulação dos militares e dos CIM's do orçamento e da opinião pública do país. Agora, a "vontade política" dos EUA formada por altos escalões políticos e militares aprofunda os complexos industriais e militares ao integrarem as novas tecnologias biológicas.

Desde o advento das guerras gerais do capitalismo e também os períodos de crise sistêmica que as estratégias imperialistas e de desenvolvimento de tecnologias de uso dual

18 Disponível em http:/ / www.gilead.com/pr_783456 acesso em 02/10/2010 (Tradução nossa).

19 Somente os royalties pagos à Roche referentes ao TAMIFLU quase alcançaram os 500 milhões de dólares 
são mobilizadas pelos países centrais para retomarem a reprodução capitalista ampliada, ainda que pela velha forma de sempre: a produção do medo.

\section{REFERÊNCIAS BIBLIOGRÁFICAS}

\section{ALBUQUERQUE, Edu S. Uma breve história da Geopolítica. Rio de Janeiro, CENEGRI, 2011.}

DAGNINO, Renato. Em que a economia de defesa pode ajudar nas decisões sobre a revitalização da Indústria de Defesa brasileira. Revista Oikos, Rio de Janeiro, nº 9, ano VII, 2008, ISSN 1808-0235.www. revistaoikos.org, pgs 113-137.

FIORI, José L. A nova geopolítica das nações e o lugar da Rússia, China, Índia, Brasil e África do Sul. Revista Oikos. Rio de Janeiro, $n^{\circ} 8$, ano VI, 2007. ISSN 1808-0235. Disponível em www.revistaoikos.org (pgs. 77-106) acesso em 07/009/2009.

Sobre o poder global. Revista novos estudos. Nov/ 2005 (pgs 61-72).

FLORES, Mario Cesar. Reflexões estratégicas: repensando a defesa nacional. São Paulo: Ed. Realizações, 2002.

GARCIA, Ana Saggioro. Hegemonia e Imperialismo: caracterizações da ordem mundial capitalista após a II Guerra Mundial. Revista On Line Trabalho Necessário, no 8, ano 10/2010. ISSN 1808-799X. Disponível em http:/ / www.uff.br/trabalhonecessario (pgs 1-20) acesso em 07/09/2009.

HARVEY, David. O Novo Imperialismo. São Paulo. Loyola, 2003.

KLEIN, Naomi. A Doutrina do Choque: A Ascensão do Capitalismo de desastre. Trad. Vania Cury. Rio de Janeiro. Nova Fronteira, 2008.

MILLER, Judith; ENGELBERG, Stephen; BROAD, William. Germes: As Armas Biológicas e a Guerra Secreta da América. Trad. Maria José Figueiredo. Rio de Janeiro: EDIOURO, 2002.

SANTOS, Milton. Por uma outra globalização: Do pensamento único à consciência universal. Rio de Janeiro: RECORD, $14^{\circ}$ ed. 2007.

UNITEDSTATES GOVERNMENT ACCOUNTABILITY OFFICE: PROJECT BIOSHIELD: Actions Needed to Avoid Repeating Past Mistakes. For Release on Delivery Expect at 10:00 am. EDT. Tuesday, October, 23/2007. Documento disponível em http:/ / www.gao.gov/new.items/d08208t.pdf acesso em 10/10/2011.

VESENTINI, José William. Terrorismo e nova ordem mundial. In:_CARVALHO, Leonardo Arquimimo de. (org.) Geopolítica e Relações Internacionais. 1ª ed. $4^{\mathrm{a}}$ tiragem, Curitiba, Juruá, 2006.

\section{REFERÊNCIAS ELETRÔNICAS}

Aspartame/Nutrasweet: Disponível em: http://www.monsanto.com.br/institucional/para_sua_ informacao/aspartame_nutrasweet.asp acesso em 20/05/2011.

Baxter, Tamiflu, Rumsfeld e gripe das aves: Contaminação e Tratamento: Disponível em: http:/ /www. lawrei.eu/MRA_Alliance/?p=3333 acesso em 05/10/2010.

Biografías y Vidas: Donald Rumsfeld: Disponível em: http://www.biografiasyvidas.com/biografia/r/ rumsfeld.htm acesso em 02/10/2010.

Bush sanciona lei para combater bioterrorismo: Disponível em: http://www.bbc.co.uk/portuguese/ reporterbbc/story/2004/07/040721_washingtonng.shtml acesso em 09/10/2011.

Donald Rumsfeld, January 20, 2001 - December 18, 2006: 21st Secretary of Defense: Disponível em: http:/ / www.defense.gov/specials/secdef_histories/bios/rumsfeld.htm acesso em 08/10/2010. 
Donald Rumsfeld Named Chairman of Gilead Sciences. Disponível em: http://www.gilead.com/wt/ sec/pr_933190157/ acesso em 19/05/2011.

Gilead and Roche End Tamiflu^; Expanded Collaboration Includes Gilead Role in Oversight of Manufacturing and Commercialization. Disponível em: http://www.gilead.com/pr_783456 acesso em 02/10/2010.

Gilead Sciences Inc. Hystory. Disponível em: http://www.fundinguniverse.com/company-histories/ Gilead-Sciences-Inc-Company-History.html acesso em 05/10/2010

VaxGen gets \$877.5 million to supply 75 million doses of anthrax vaccine. Disponível em http://www. news-medical.net/news/2004/11/04/6115.aspx acesso em 15/10/2011.

VaxGen signs definite agreement to acquire diaDexus in stock-for-stock merger. Disponível em: http://www.news-medical.net/news/20100529/25/Portuguese.aspx acesso em 09/10/2011.

Recebido em 13/02/2012

Aceito para publicação em 25/05/2012 